\title{
Convergence of Common Random Fixed Point of Finite Family of Asymptotically Quasi-Nonexpansive-Type Mappings by an Implicit Random Iterative Scheme
}

\author{
A. S. Saluja ${ }^{1}$ and Pankaj kumar Jhade ${ }^{2}$ \\ ${ }^{1}$ Department of Mathematics, J. H. Government PG College, Betul 460001, India \\ ${ }^{2}$ Department of Mathematics, NRI Institute of Information Science \& Technology, Bhopal 462021, India \\ Correspondence should be addressed to Pankaj kumar Jhade; pmathsjhade@gmail.com
}

Received 26 October 2012; Revised 5 February 2013; Accepted 6 February 2013

Academic Editor: Zindoga Mukandavire

Copyright ( $) 2013$ A. S. Saluja and P. K. Jhade. This is an open access article distributed under the Creative Commons Attribution License, which permits unrestricted use, distribution, and reproduction in any medium, provided the original work is properly cited.

We introduce a new implicit random iteration process generated by a finite family of asymptotically quasi-nonexpansive-type mappings and study necessary and sufficient conditions for the convergence of this process in a uniformly convex Banach space. The results presented in this paper extend and improve the recent ones announced by Plubtieng et al. (2007), Beg and Thakur (2009), and Saluja and Nashine (2012).

\section{Introduction}

Probabilistic functional analysis has come out as one of the momentous mathematical disciplines in view of its requirements in dealing with probabilistic models in applied problems. The study of random fixed points forms a central topic in this area. Random fixed point theorems for random contraction mappings on separable complete metric spaces were first proven by Špaček [1]. Subsequently, Bharucha-Reid [2] has given sufficient conditions for a stochastic analog of Schauder's fixed point theorem for a random operator. The study of random fixed point theorems was initiated by Špaček [1] and Hanš $[3,4]$. In an attempt to construct iterations for finding fixed points of random operators defined on linear spaces, random Ishikawa scheme was introduced in [5]. This iteration and also some other random iterations based on the same ideas have been applied for finding solutions of random operator equations and fixed points of random operators (see [5]).

Recently, Beg [6], Choudhury [7], Duan and Li [8], Li and Duan [9], Itoh [10], and many others have studied the fixed point of random operators. Beg and Abbas [11] studied the different random iterative algorithms for weakly contractive and asymptotically nonexpansive random operators on arbitrary Banach spaces. They also established the convergence of an implicit random iterative process to a common random fixed point for a finite family of asymptotically quasinonexpansive operators.

In 2007, Plubtieng et al. [12] studied the implicit random iteration process with errors, which converges strongly to a common fixed point of a finite family of asymptotically quasi-nonexpansive random operators on an unbounded set in uniformly convex Banach spaces and proves some strong convergence theorems.

An implicit process is generally desirable when no explicit scheme is available. Such a process is generally used as a "tool" to establish the convergence of an explicit scheme.

Recently, Beg and Thakur [13] introduced modified general composite implicit random iteration process and proved some strong convergence theorems for a finite family of random asymptotically nonexpansive mappings in separable Banach spaces.

Very recently, Saluja and Nashine [14] introduced a new modified general composite implicit random iteration process to give necessary and sufficient conditions for strong 
convergence of the iteration process to a common random fixed point of a finite family of asymptotically quasinonexpansive in the intermediate sense random operators in separable Banach spaces.

Motivated and inspired by the above work, in this paper, we introduced a new implicit random iteration process generated by a finite family of asymptotically quasi-nonexpansivetype random operators with mixed errors in a uniformly convex Banach spaces and give necessary and sufficient conditions for the convergence of the proposed iteration process to a common random fixed point. The results presented in this paper extend and improve the results of Plubtieng et al. [12], Beg and Thakur [13], Saluja and Nashine [14], and some others.

\section{Preliminaries}

Let $(\Omega, \Sigma)$ be a measurable space with $\Sigma$, a sigma algebra of $\Omega$, and let $C$ be a nonempty subset of a Banach space $X$. A mapping $\xi: \Omega \rightarrow X$ is measurable if $\xi^{-1}(U) \in \Sigma$ for each open subset $U$ of $X$. The mapping $T: \Omega \times C \rightarrow C$ is a random map if for each fixed $x \in C$, the mapping $T(\cdot, x): \Omega \rightarrow C$ is measurable, and it is continuous if for each $\omega \in \Omega$, the mapping $T(\omega, \cdot): C \rightarrow X$ is continuous. A measurable mapping $\xi: \Omega \rightarrow X$ is the random fixed point of the random map $T: \Omega \times C \rightarrow C$ if $T(\omega, \xi(\omega))=\xi(\omega)$, for each $\omega \in \Omega$. We denote by $\mathrm{RF}(T)$ and $\mathrm{D}(T)$ the set of all random fixed points of a random map and the domain of the random map $T: \Omega \times C \rightarrow C$, respectively, and by $T^{n}(\omega, x)$ the $n$th iterate $T(\omega, T(\omega, T(\omega, \ldots, T(\omega, x)))$ of $T$. The letter $I$ denotes the random mapping $I: \Omega \times C \rightarrow C$, defined by $I(\omega, x)=x$ and $T^{0}=I$.

Definition 1. Let $C$ be a nonempty subset of a separable Banach space $X$ and let $T: D(T) \subset \Omega \times C \rightarrow C$ be a random map. The map $T$ is said to be

(a) a nonexpansive random operator iffor arbitrary $x, y \in$ $D(T)$, one has

$$
\|T(\omega, x)-T(\omega, y)\| \leq\|x-y\|
$$

for each $\omega \in \Omega$ and $x, y \in D(T)$;

(b) a quasi-nonexpansive random operator if $F(T) \neq \emptyset$ and

$$
\|T(\omega, x)-\xi(\omega)\| \leq\|x-\xi(\omega)\|
$$

for all $x \in D(T)$ and $\xi(\omega) \in F$;

(c) an asymptotically nonexpansive random operator if there exists a sequence of measurable mappings $r_{n}$ : $\Omega \rightarrow[0, \infty)$ with $\lim _{n \rightarrow \infty} r_{n}(\omega)=0$ for each $\omega \in \Omega$, such that for arbitrary $x, y \in D(T)$,

$$
\left\|T^{n}(\omega, x)-T^{n}(\omega, y)\right\| \leq\left(1+r_{n}(\omega)\right)\|x-y\| ;
$$

(d) an asymptotically quasi-nonexpansive random operator if $F(T) \neq \phi$ and there exists a sequence of measurable mappings $r_{n}: \Omega \rightarrow[0, \infty)$ with $\lim _{n \rightarrow \infty} r_{n}(\omega)=0$ for each $\omega \in \Omega$ such that for arbitrary $x \in \mathrm{D}(T)$ and $\xi(\omega) \in F(T)$,

$$
\left\|T^{n}(\omega, x)-\xi(\omega)\right\| \leq\left(1+r_{n}(\omega)\right)\|x-\xi(\omega)\| ;
$$

(e) an asymptotically nonexpansive type if

$\lim _{n \rightarrow \infty} \sup \left\{\sup _{x \in D(T)}\left(\left\|T^{n}(\omega, x)-T^{n}(\omega, y)\right\|-\|x-y\|\right)\right\} \leq 0$

for all $y \in D(T)$ and $n \geq 0$;

(f) an asymptotically quasi-nonexpansive-type random operator if $F(T) \neq \phi$ and

$$
\lim _{n \rightarrow \infty} \sup \left\{\sup _{x \in D(T)}\left(\left\|T^{n}(\omega, x)-\xi(\omega)\right\|-\|x-\xi(\omega)\|\right)\right\} \leq 0
$$

for all $\xi(\omega) \in F(T)$ and $n \geq 0 ;$

(g) a uniformly $L$-Lipschitzian random operator if for arbitrary $x, y \in D(T)$, one has

$$
\left\|T^{n}(\omega, x)-T^{n}(\omega, y)\right\| \leq L\|x-y\|,
$$

where $n \geq 0$ and $L$ is a positive constant.

Remark 2. We know that the following implications hold from the definitions:

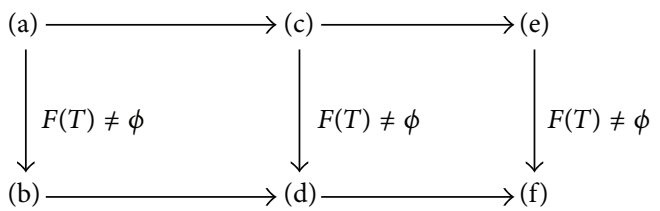

Example 3. Let $C$ be the real line with the usual norm $|\cdot|$ and $\Omega=[0,1]$. Define $T: \Omega \times C \rightarrow C$ by $T(\omega, x)=\sin x, x \in$ $[0,1]$ for $x \in C$ and $\omega \in \Omega$. Obviously $T(\omega, 0)=0$; that is, 0 is a fixed point of $T$; that is, $\operatorname{RF}(T)=\{0\}$. Now we check that $T$ is asymptotically quasi-nonexpansive-type random operator. In fact, if $x \in[0,1]$ and $\xi(\omega)=0 \in[0,1]$, then

$$
\begin{aligned}
|T(\omega, x)-\xi(\omega)| & =|T(\omega, x)-0|=|\sin x| \leq|x| \\
& =|x-0|=|x-\xi(\omega)|
\end{aligned}
$$

that is,

$$
|T(\omega, x)-\xi(\omega)| \leq|x-\xi(\omega)|
$$

Thus, $T$ is quasi-nonexpansive. It follows that $T$ is asymptotically quasi-nonexpansive with $\lim _{n \rightarrow \infty} r_{n}=0$ for each $n \geq 1$, and hence it is asymptotically quasi-nonexpansivetype random operator.

(h) The map $T$ is a semi compact random operator if for a sequence of measurable mappings $\left\{\xi_{n}\right\}$ from $\Omega$ to $C$, with $\lim _{n \rightarrow \infty}\left\|\xi_{n}(\omega)-T\left(\omega, \xi_{n}(\omega)\right)\right\|=0$ for every $\omega \in \Omega$, one has a subsequence $\left\{\xi_{n_{k}}\right\}$ of $\left\{\xi_{n}\right\}$ and a measurable mapping $\xi: \Omega \rightarrow C$ such that $\left\{\xi_{n_{k}}\right\}$ converges pointwise to $\xi$ as $k \rightarrow \infty$. 
(i) A Banach space $C$ is said to be uniformly convex if the modulus of convexity of $C$ (see [15])

$$
\delta_{C}(\varepsilon)=\inf \left\{1-\frac{1}{2}\|x+y\|:\|x\|=\|y\|=1,\|x-y\|=\varepsilon\right\}>0
$$

for all $0<\varepsilon \leq 2$ (i.e., $\delta_{C}(\varepsilon)$ is a function $\left.(0,1] \rightarrow(0,1]\right)$.

Definition 4 (modified general composite iteration process, cf. [14]). Let $\left\{T_{i}\right\}_{i=1}^{N}$ be a family of asymptotically quasinonexpansive in the intermediate sense random operators from $\Omega \times C$ to $C$, where $C$ is a closed, convex subset of a separable Banach space $X$ with $F=\bigcap_{i=1}^{N} \operatorname{RF}\left(T_{i}\right) \neq \phi$. Let $\xi_{0}: \Omega \rightarrow C$ be any fixed measurable map, then the sequence of function $\left\{\xi_{n}\right\}$ defined by

$$
\begin{gathered}
\xi_{n}(\omega)=\alpha_{n} \xi_{n-1}(\omega)+\left(1-\alpha_{n}\right) T_{i(n)}^{k(n)}\left(\omega, \eta_{n}(\omega)\right), \quad \forall n \geq 1, \\
\eta_{n}(\omega)=a_{n} \xi_{n}(\omega)+b_{n} \xi_{n-1}(\omega)+c_{n} T_{i(n)}^{k(n)}\left(\omega, \xi_{n}(\omega)\right) \\
+d_{n} T_{i(n)}^{k(n)}\left(\omega, \xi_{n-1}(\omega)\right), \quad \forall n \geq 1,
\end{gathered}
$$

where $\left\{\alpha_{n}\right\},\left\{a_{n}\right\},\left\{b_{n}\right\},\left\{c_{n}\right\},\left\{d_{n}\right\} \subset[0,1]$ with $a_{n}+b_{n}+c_{n}+d_{n}=$ $1, n=(k-1) N+i$, where $i=i(n) \in\{1,2, \ldots, N\}, k=$ $k(n) \geq 1$ is a positive integer, and $k(n) \rightarrow \infty$ as $n \rightarrow \infty$.

Now we introduce the two-step implicit random iterative process with mixed errors for a finite family of asymptotically quasi-nonexpansive-type random operators in a Banach space $C$ as follows.

Definition 5 (two-step implicit random iterative scheme). Let $T_{i}: \Omega \times C \rightarrow C$ be random operators $(i=1,2, \ldots, N)$, where $C$ is a nonempty convex subset of a separable Banach space $X$. Let $\xi_{0}: \Omega \rightarrow C$ be a measurable mapping from $\Omega$ to $C$ and let $\left\{f_{n}\right\}$ and $\left\{f_{n}^{\prime}\right\}$ be bounded sequences of measurable functions from $\Omega$ to $C$. Define sequences of functions $\left\{\xi_{n}\right\}$ and $\left\{\eta_{n}\right\}$ as given below:

$$
\begin{aligned}
& \xi_{1}(\omega)=\left(1-\alpha_{1}\right) \xi_{0}(\omega)+\alpha_{1} T_{1}\left(\omega, \eta_{1}(\omega)\right)+f_{1}, \\
& \eta_{1}(\omega)=\left(1-\beta_{1}\right) \xi_{1}(\omega)+\beta_{1} T_{1}\left(\omega, \xi_{1}(\omega)\right)+f_{1}^{\prime}, \\
& \vdots \\
& \xi_{N}(\omega)=\left(1-\alpha_{N}\right) \xi_{N-1}(\omega)+\alpha_{N} T_{N}\left(\omega, \eta_{N}(\omega)\right)+f_{N}, \\
& \eta_{N}(\omega)=\left(1-\beta_{N}\right) \xi_{N}(\omega)+\beta_{N} T_{N}\left(\omega, \xi_{N}(\omega)\right)+f_{N}^{\prime}, \\
& \xi_{N+1}(\omega)=\left(1-\alpha_{N+1}\right) \xi_{N}(\omega)+\alpha_{N+1} T_{N+1}^{2}\left(\omega, \eta_{N+1}(\omega)\right)+f_{N+1}, \\
& \eta_{N+1}(\omega)=\left(1-\beta_{N+1}\right) \xi_{N+1}(\omega)+\beta_{N+1} T_{N+1}^{2}\left(\omega, \xi_{N+1}(\omega)\right)+f_{N+1}^{\prime}
\end{aligned}
$$

which can be written in the following compact form:

$$
\begin{array}{cc}
\xi_{n}(\omega)=\left(1-\alpha_{n}\right) \xi_{n-1}(\omega)+\alpha_{n} T_{i}^{k}\left(\omega, \eta_{n}(\omega)\right)+f_{n}, & n \geq 1, \\
\eta_{n}(\omega)=\left(1-\beta_{n}\right) \xi_{n}(\omega)+\beta_{n} T_{i}^{k}\left(\omega, \xi_{n}(\omega)\right)+f_{n}^{\prime}, & n \geq 1,
\end{array}
$$

where $n=(k-1) N+i(i \in I)$.

As a matter of fact, denote the indexing set $\{1,2,3, \ldots, N\}$ by $I$. Let $\left\{T_{i}: i \in I\right\}$ be $N$ uniformly $L$-Lipschitzian asymptotically quasi-nonexpansive-type random operators from $\Omega \times C \rightarrow C$. We show that the scheme (14) exists.

Let $\xi_{0}: \Omega \rightarrow C$ and $\xi_{1}(\omega)=\left(1-\alpha_{1}\right) \xi_{0}(\omega) \alpha_{1} T_{1}(\omega,(1-$ $\left.\left.\beta_{1}\right) \xi_{1}(\omega)+\beta_{1} T_{1}\left(\omega, \xi_{1}(\omega)\right)+f_{1}\right)+f_{1}^{\prime}$.

Define $W(\omega, x): D(T) \subset \Omega \times C \rightarrow C$, for all $x \in$ $D(T), \omega \in \Omega$ by

$$
\begin{aligned}
W(\omega, x)= & \left(1-\alpha_{1}\right) \xi_{0}(\omega) \alpha_{1} T_{1} \\
& \times\left(\omega,\left(1-\beta_{1}\right) x+\beta_{1} T_{1}(\omega, x)+f_{1}\right)+f_{1}^{\prime}
\end{aligned}
$$

for all $x \in D(T), \omega \in \Omega$. The existence of $\xi_{1}(\omega)$ is guaranteed if $W$ has a fixed point.

For any $x, y \in D(T)$ and $\omega \in \Omega$, we have

$$
\|W(\omega, x)-W(\omega, y)\| \leq \alpha_{1} \beta_{1} L^{2}\|x-y\| .
$$

Now $W$ is a contraction if $\alpha_{1} \beta_{1} L^{2}<1$ or $L=\left(1 / \sqrt{\alpha_{1} \beta_{1}}\right)$. As $\alpha_{1}, \beta_{1} \in[0,1]$, therefore $W$ is a contraction. By the Banach contraction principle, $W$ has a unique fixed point. Thus, the existence of $\xi_{1}(\omega)$ is established. Similarly, we can establish the existence of $\xi_{2}(\omega), \xi_{3}(\omega), \ldots$. Thus, the implicit algorithm (14) is well defined.

In the sequel, we will need the following lemmas.

Lemma 6 (see [16]). Let $\left\{a_{n}\right\}$ and $\left\{b_{n}\right\}$ be two nonnegative sequences satisfying

$$
a_{n+1} \leq a_{n}+b_{n} \quad \forall n \geq n_{0}
$$

where $\sum_{n=1}^{\infty} b_{n}<\infty$ and $n_{0}$ is some positive integer. Then $\lim _{n \rightarrow \infty} a_{n}$ exists.

Lemma 7 (see [17]). Let $p>1$ and $r>0$ be two fixed real numbers. Then a Banach space $C$ is uniformly convex if and only if there exists a continuous strictly increasing convex function $g:[0, \infty) \rightarrow[0, \infty)$ with $g(0)=0$ such that

$$
\begin{array}{r}
\|\lambda x+(1-\lambda) y\|^{p} \leq \lambda\|x\|^{p}+(1-\lambda)\|y\|^{p} \\
-w_{p}(\lambda) g(\|x-y\|)
\end{array}
$$

for all $x, y \in B_{r}=\{x \in C:\|x\| \leq r\}$ and $\lambda \in[0,1]$, where $w_{p}(\lambda)=\lambda^{p}(1-\lambda)+\lambda(1-\lambda)^{p}$.

Lemma 8 (see [18]). Let $p>1$ be a given real number. Then for any $a \geq 0$ and $b \geq 0$, there exists a nonnegative real number $c$ between $a$ and $a+b$ such that $(a+b)^{p}=a^{p}+p c^{p-1} b$. 


\section{Main Results}

In this section, we investigate the convergence of an implicit random iterative process with mixed errors for a finite family of asymptotically quasi-nonexpansive-type random operators to obtain the random solution of the common random fixed point in a uniformly convex separable Banach space.

Before proving our main results, we first prove the following crucial lemma.

Lemma 9. Let $X$ be a uniformly convex separable Banach space and let $C$ be a nonempty closed and convex subset of $X$. Let, for each $i \in I, T_{i}: D(T) \subset \Omega \times C \rightarrow C$ be asymptotically quasi-nonexpansive-type random operators. Suppose that $\mathscr{F}=$ $\bigcap_{i=1}^{N} \operatorname{RF}\left(T_{i}\right) \neq \phi$. Let $\xi_{0}: \Omega \rightarrow C$ be measurable mapping and let $\left\{\xi_{n}(\omega)\right\}$ be a sequence defined by the implicit random iterative scheme (14) with mixed errors satisfying the following conditions:

(i) $s<\alpha_{n}<1-s$ for some $s \in(0,1 / 2)$;

(ii) $\sum_{n=0}^{\infty} \alpha_{n}<\infty$;

(iii) $\left\{f_{n}\right\}$ and $\left\{f_{n}^{\prime}\right\}$ are bounded, $f_{n}=f_{n}^{\prime \prime}+f_{n}^{\prime \prime \prime}(n \geq 0)$ and $\sum_{n=0}^{\infty}\left\|f_{n}^{\prime \prime}\right\|<\infty,\left\|f_{n}^{\prime \prime \prime}\right\|=o\left(\alpha_{n}\right)$.

Note. It is pointed out that in condition (iii), $\left\|f_{n}^{\prime \prime \prime}\right\|=o\left(\alpha_{n}\right)$ for all $n \geq 0$ is equivalent to that there exists a sequence $\left\{\varepsilon_{n}\right\}$ with $\varepsilon_{n} \geq 0$ and $\varepsilon_{n} \rightarrow 0$ as $n \rightarrow \infty$ such that $\left\|f_{n}^{\prime \prime \prime}\right\|=\varepsilon_{n} \alpha_{n}$ for all $n \geq 0$.

Then for any given $\varepsilon>0$, there exists $M(\omega)>0$ for each $\omega \in \Omega$, such that

(1) $\left\|\xi_{n}(\omega)-\xi(\omega)\right\| \leq\left\|\xi_{n-1}(\omega)-\xi(\omega)\right\|+(M(\omega) / s) \alpha_{n}+$ $(1 / s)\left\|f_{n}^{\prime \prime}\right\|$ for all $\xi(\omega) \in \mathscr{F}, n \geq 0$;

(2) $\left\|\xi_{n+m}(\omega)-\xi(\omega)\right\| \leq\left\|\xi_{n}(\omega)-\xi(\omega)\right\|+$ $(M(\omega) / s) \sum_{l=n+1}^{n+m} \alpha_{l}+(1 / s) \sum_{l=n+1}^{n+m}\left\|f_{l}^{\prime \prime}\right\|$ for all $n \geq 0 m \geq 1$, where $M(\omega)=(2 / 5) \varepsilon+\sup _{n \geq 0}\left\{\left\|f_{n}^{\prime}\right\|+\right.$ $\left.\varepsilon_{n}\right\}<\infty$ and $\left\{\varepsilon_{n}\right\}$ is the positive sequence appearing in the note of Lemma 9;

(3) $\lim _{n \rightarrow \infty} D\left(\xi_{n}(\omega), \mathscr{F}\right)$ exists.

Proof. Let $\xi(\omega) \in \mathscr{F}$, from (14), where $n=(k-1) N+i, T_{n} \equiv$ $T_{n(\bmod N)}=T_{i}(i \in I)$; it follows that

$$
\begin{aligned}
\left\|\xi_{n}(\omega)-\xi(\omega)\right\|= & \|\left(1-\alpha_{n}\right)\left(\xi_{n-1}(\omega)-\xi(\omega)\right) \\
& +\alpha_{n}\left(T_{i}^{k}\left(\omega, \eta_{n}(\omega)\right)-\xi(\omega)\right)+f_{n} \| \\
\leq & \left(1-\alpha_{n}\right)\left\|\xi_{n-1}(\omega)-\xi(\omega)\right\| \\
& +\alpha_{n}\left(\left\|T_{i}^{k}\left(\omega, \eta_{n}(\omega)\right)-\xi(\omega)\right\|\right. \\
& \left.-\left\|\eta_{n}(\omega)-\xi(\omega)\right\|\right) \\
& +\alpha_{n}\left\|\eta_{n}(\omega)-\xi(\omega)\right\|+\left\|f_{n}\right\|,
\end{aligned}
$$

$$
\begin{aligned}
\left\|\eta_{n}(\omega)-\xi(\omega)\right\|= & \|\left(1-\beta_{n}\right)\left(\xi_{n}(\omega)-\xi(\omega)\right) \\
& +\beta_{n}\left(T_{i}^{k}\left(\omega, \xi_{n}(\omega)\right)-\xi(\omega)\right)+f_{n}^{\prime \prime} \| \\
\leq & \left(1-\beta_{n}\right)\left\|\xi_{n}(\omega)-\xi(\omega)\right\| \\
& +\beta_{n}\left(\left\|T_{i}^{k}\left(\omega, \xi_{n}(\omega)\right)-\xi(\omega)\right\|\right. \\
& \left.\quad-\left\|\xi_{n}(\omega)-\xi(\omega)\right\|\right) \\
& +\beta_{n}\left\|\xi_{n}(\omega)-\xi(\omega)\right\|+\left\|f_{n}^{\prime \prime}\right\| \\
= & \left\|\xi_{n}(\omega)-\xi(\omega)\right\| \\
& +\beta_{n}\left(\left\|T_{i}^{k}\left(\omega, \xi_{n}(\omega)\right)-\xi(\omega)\right\|\right. \\
& \left.-\left\|\xi_{n}(\omega)-\xi(\omega)\right\|\right)+\left\|f_{n}^{\prime \prime}\right\| .
\end{aligned}
$$

From Definition 1, for any given $\varepsilon>0$, there exists a positive integer $n_{0}$ such that $n \geq n_{0}$; that is, $k>\left(n_{0} / N\right)+1$. We have

$$
\sup _{x \in D(T)}\left\{\left\|T_{i}^{n}(\omega, x)-\xi(\omega)\right\|-\|x-\xi(\omega)\|\right\} \leq \frac{\varepsilon}{6}
$$

for all $\xi(\omega) \in \mathscr{F}$.

Since $\left\{\xi_{n}\right\},\left\{\eta_{n}\right\} \subset X$, we have

$$
\begin{array}{r}
\left\|T_{i}^{n}\left(\omega, \xi_{n}(\omega)\right)-\xi(\omega)\right\|-\left\|\xi_{n}(\omega)-\xi(\omega)\right\|<\frac{\varepsilon}{5} \\
\forall \xi(\omega) \in \mathscr{F}, n \geq n_{0}, \\
\left\|T_{i}^{n}\left(\omega, \eta_{n}(\omega)\right)-\xi(\omega)\right\|-\left\|\xi_{n}(\omega)-\xi(\omega)\right\|<\frac{\varepsilon}{5} \\
\forall \xi(\omega) \in \mathscr{F}, n \geq n_{0}
\end{array}
$$

for each $i \in I$.

Substituting (22) in (20), we obtain

$$
\begin{array}{r}
\left\|\eta_{n}(\omega)-\xi(\omega)\right\| \leq\left\|\xi_{n}(\omega)-\xi(\omega)\right\|+\frac{\varepsilon}{5} \beta_{n}+\left\|f_{n}^{\prime}\right\| \\
\forall \xi(\omega) \in \mathscr{F}, n \geq n_{0} .
\end{array}
$$

Next considering the fourth term in the right side of (19), we have

$$
\left\|f_{n}\right\| \leq\left\|f_{n}^{\prime \prime}\right\|+\left\|f_{n}^{\prime \prime \prime}\right\|
$$

for all $n \geq 0$.

From the Note of Lemma 9 given previously, we have

$$
\left\|f_{n}\right\| \leq\left\|f_{n}^{\prime \prime}\right\|+\varepsilon_{n} \alpha_{n}
$$

for all $n \geq n_{0}$, where $\left\{\varepsilon_{n}\right\}$ is a positive sequence with $\lim _{n \rightarrow \infty} \varepsilon_{n}=0$. 
Substituting (23)-(26) into (19), we obtain

$$
\begin{aligned}
\left\|\xi_{n}(\omega)-\xi(\omega)\right\| \leq & \left(1-\alpha_{n}\right)\left\|\xi_{n-1}(\omega)-\xi(\omega)\right\|+\alpha_{n} \frac{\varepsilon}{5} \\
& +\alpha_{n}\left\{\left\|\xi_{n}(\omega)-\xi(\omega)\right\|+\beta_{n} \frac{\varepsilon}{5}+\left\|f_{n}^{\prime}\right\|\right\} \\
& +\left\|f_{n}^{\prime \prime}\right\|+\varepsilon_{n} \alpha_{n}
\end{aligned}
$$

for all $n \geq 0, \xi(\omega) \in \mathscr{F}$.

From condition (i), we have

$$
1<\frac{1-\alpha_{n}}{s}, \quad \frac{1}{1-\alpha_{n}}<\frac{1}{s}
$$

for all $n \geq 0$.

Thus, from (27) we know that

$$
\begin{aligned}
\left(1-\alpha_{n}\right)\left\|\xi_{n}(\omega)-\xi(\omega)\right\| \leq & \left(1-\alpha_{n}\right)\left\|\xi_{n-1}(\omega)-\xi(\omega)\right\| \\
& +\alpha_{n} \frac{1-\alpha_{n}}{s}\left\{\frac{\varepsilon}{5}\left(1+\beta_{n}\right)+\left\|f_{n}^{\prime}\right\|+\varepsilon_{n}\right\} \\
& +\left\|f_{n}^{\prime \prime}\right\|, \\
\left\|\xi_{n}(\omega)-\xi(\omega)\right\| \leq & \left\|\xi_{n-1}(\omega)-\xi(\omega)\right\| \\
& +\frac{\alpha_{n}}{s}\left\{\frac{\varepsilon}{5}\left(1+\beta_{n}\right)+\left\|f_{n}^{\prime}\right\|+\varepsilon_{n}\right\} \\
& +\frac{1}{s}\left\|f_{n}^{\prime \prime}\right\|
\end{aligned}
$$

for all $n \geq 0$ and for all $\xi(\omega) \in \mathscr{F}$.

Since $\lim _{n \rightarrow \infty} \varepsilon_{n}=0$ and $\left\{f_{n}^{\prime}\right\}$ is bounded in $C,\left\{\beta_{n}\right\}$ is a real sequence in $[0,1]$; let

$$
M(\omega)=\frac{2}{5} \varepsilon+\sup _{n \geq 0}\left\{\left\|f_{n}^{\prime}\right\|+\varepsilon_{n}\right\}<\infty .
$$

Then we have

$$
\left\|\xi_{n}(\omega)-\xi(\omega)\right\| \leq\left\|\xi_{n-1}(\omega)-\xi(\omega)\right\|+\frac{M(\omega)}{s} \alpha_{n}+\frac{1}{s}\left\|f_{n}^{\prime \prime}\right\|
$$

for all $n \geq 0$ and for all $\xi(\omega) \in \mathscr{F}$.

Conclusion (1) is proved.

Again it follows from conclusion (1) that for any $m \geq 1$, we obtain

$$
\begin{aligned}
& \left\|\xi_{n+m}(\omega)-\xi(\omega)\right\| \\
& \leq\left\|\xi_{n+m-1}(\omega)-\xi(\omega)\right\|+\frac{M(\omega)}{s} \alpha_{n+m}+\frac{1}{s}\left\|f_{n+m}^{\prime \prime}\right\| \\
& \leq\left\|\xi_{n+m-2}(\omega)-\xi(\omega)\right\|+\frac{M(\omega)}{s}\left(\alpha_{n+m-1}+\alpha_{n+m}\right) \\
& \quad+\frac{1}{s}\left(\left\|f_{n+m-1}^{\prime \prime}\right\|+\left\|f_{n+m}^{\prime \prime}\right\|\right) \\
& \leq\left\|\xi_{n}(\omega)-\xi(\omega)\right\|+\frac{M(\omega)}{s} \sum_{l=n+1}^{n+m} \alpha_{l}+\frac{1}{s} \sum_{l=n+1}^{n+m}\left\|f_{l}^{\prime \prime}\right\|
\end{aligned}
$$

for all $n \geq 0$ and for all $\xi(\omega) \in \mathscr{F}$.

Thus, conclusion (2) is proved.
Similarly from conclusion (1), it is easy to see that

$$
D\left(\xi_{n}(\omega), \mathscr{F}\right) \leq D\left(\xi_{n-1}(\omega), \mathscr{F}\right)+\frac{M(\omega)}{s}+\alpha_{n}+\frac{1}{s}\left\|f_{n}^{\prime \prime}\right\|
$$

for all $n \geq 0$.

By conditions (i), (ii), $\sum_{n=0}^{\infty}\left((M(\omega) / s) \alpha_{n}+(1 / s)\left\|f_{n}^{\prime \prime}\right\|\right)<$ $\infty$.

Hence, from Lemma 6 we know that $\left(\lim _{n \rightarrow \infty} D\left(\xi_{n}(\omega), \mathscr{F}\right)\right.$ exists.

This proves conclusion (3) and hence completes the proof of the lemma.

Theorem 10. Let $X$ be a uniformly convex separable Banach space and let $C$ be a nonempty closed and convex subset of $X$. Let, for each $i \in I, T_{i}: D(T) \subset \Omega \times C \rightarrow C$ be asymptotically quasi-nonexpansive-type random operators satisfying the following condition: there exists constant $L_{i}>0$ and $a_{i}>0$ such that

$$
\left\|T_{i}(\omega, x)-\xi(\omega)\right\| \leq L_{i}\|\| x-\xi(\omega)\|\|^{a_{i}}
$$

for all $x \in D(T), \xi(\omega) \in \mathscr{F}$, and $i \in I$. Suppose that $\mathscr{F}=$ $\bigcap_{i=1}^{N} \operatorname{RF}\left(T_{i}\right) \neq \phi$. Let $\xi_{0}: \Omega \rightarrow C$ be measurable mapping and let $\left\{\xi_{n}(\omega)\right\}$ be sequence defined by the implicit random iterative scheme (14) with mixed errors satisfying the conditions (i)-(iii) of Lemma 9.

Then $\left\{\xi_{n}\right\}$ converges strongly to a common random fixed point of $\mathscr{F}$ if and only if

$$
\lim _{n \rightarrow \infty} \inf D\left(\xi_{n}(\omega), \mathscr{F}\right)=0
$$

Proof. The necessity is obvious. We will only prove the sufficiency. Suppose that condition (35) is satisfied. Then from Lemma 9(3), we have

$$
\lim _{n \rightarrow \infty} D\left(\xi_{n}(\omega), \mathscr{F}\right)=0
$$

Now first we prove that $\left\{\xi_{n}\right\}$ is a Cauchy sequence. In fact, by conditions (ii), (iii) and (36), for given $\varepsilon>0$, there exists a positive integer $n_{1}$ such that for any $n \geq n_{1}^{\prime}=\max \left\{n_{1}, n_{0}\right\}$ (where $n_{0}$ is the positive integer appeared in Lemma 9), we have

$$
\begin{gathered}
D\left(\xi_{n}(\omega), \mathscr{F}\right)<\frac{\varepsilon}{7} \\
\sum_{i=1}^{N} \sum_{k=\left[\left(n_{1}^{\prime}+1\right) / N\right]}^{\infty} \alpha_{k i}<\frac{s \mathcal{E}}{3 M(\omega)}, \quad \sum_{i=1}^{N} \sum_{k=\left[\left(n_{1}^{\prime}+1\right) / N\right]}^{\infty}\left\|f_{k i}^{\prime \prime}\right\|<\frac{s \varepsilon}{3} .
\end{gathered}
$$

By the definition of infimum, it follows from (37) that for any given $n \geq n_{1}^{\prime}$, there exists a $\xi^{*}(\omega) \in \mathscr{F}$ such that

$$
\left\|\xi(\omega)-\xi^{*}(\omega)\right\|<\frac{\varepsilon}{6} .
$$


On the other hand, it follows from Lemma 9(2) that for the given $\varepsilon>0$ and for any $n \geq n_{1}^{\prime}$, we have

$$
\begin{aligned}
& \left\|\xi_{n+m}(\omega)-\xi_{n}(\omega)\right\| \\
& \leq\left\|\xi_{n+m}(\omega)-\xi^{*}(\omega)\right\|+\left\|\xi_{n}(\omega)-\xi^{*}(\omega)\right\| \\
& \leq\left\|\xi_{n}(\omega)-\xi^{*}(\omega)\right\|+\frac{M(\omega)}{s} \sum_{l=n+1}^{n+m} \alpha_{l} \\
& \quad+\frac{1}{s} \sum_{l=n+1}^{n+m}\left\|f_{l}^{\prime \prime}\right\|+\left\|\xi_{n}(\omega)-\xi^{*}(\omega)\right\| \\
& <2\left\|\xi_{n}(\omega)-\xi^{*}(\omega)\right\|+\frac{M(\omega)}{s} \sum_{i=1}^{N} \sum_{k=[(n+1) / N]}^{\infty} \alpha_{k i} \\
& +\frac{1}{s} \sum_{i=1}^{N} \sum_{k=[(n+1) / N]}^{\infty}\left\|f_{k i}^{\prime \prime}\right\|,
\end{aligned}
$$

where $M(\omega)=(2 / 5) \varepsilon+\sup _{n \geq 0}\left\{\left\|f_{n}^{\prime}\right\|+\varepsilon_{n}\right\}<\infty$.

Therefore, from (38)-(40), for any $n \geq n_{1}^{\prime}$, we have

$$
\left\|\xi_{n+m}(\omega)-\xi_{n}(\omega)\right\|<\frac{\varepsilon}{3}+\frac{\varepsilon}{3}+\frac{\varepsilon}{3}=\varepsilon \quad \forall m \geq 1 .
$$

This implies that $\left\{\xi_{n}\right\}$ is a Cauchy sequence. Since the space is complete, the sequence $\left\{\xi_{n}\right\}$ is convergent; let $\lim _{n \rightarrow \infty} \xi_{n}(\omega)=$ $\xi^{\prime}(\omega)$.

Now, we prove that $\xi^{\prime}(\omega)$ is a common fixed point of $T_{i}$.

Since $\lim _{n \rightarrow \infty} \xi_{n}(\omega)=\xi^{\prime}(\omega)$ and $\lim _{n \rightarrow \infty} D\left(\xi_{n}(\omega), \mathscr{F}\right)=$ 0 , for given $\varepsilon>0$, there exists a positive integer $n_{2}$ such that for $n \geq n_{2}=\max \left\{n_{2}, n_{1}^{\prime}\right\}$, we have

$$
\left\|\xi_{n}(\omega)-\xi^{\prime}(\omega)\right\|<\frac{\varepsilon}{5}, \quad D\left(\xi_{n}(\omega), \mathscr{F}\right)<\frac{\varepsilon}{7} .
$$

It follows from the second inequality in (42) that there exists $\xi^{\prime \prime}(\omega) \in \mathscr{F}$ such that

$$
\left\|\xi_{n_{2}^{\prime}}(\omega)-\xi^{\prime \prime}(\omega)\right\|<\frac{\varepsilon}{5}
$$

Moreover, it follows from (21) that for any $n \geq n_{2}^{\prime}$, we have

$$
\left\|T_{i}^{n}\left(\omega, \xi^{\prime}(\omega)\right)-\xi^{\prime \prime}(\omega)\right\|-\left\|\xi^{\prime}(\omega)-\xi^{\prime \prime}(\omega)\right\|<\frac{\varepsilon}{5} .
$$

Therefore, from (42)-(44), for any $n \geq n_{2}^{\prime}$, we have

$$
\begin{aligned}
\left\|T_{i}^{n}\left(\omega, \xi^{\prime}(\omega)\right)-\xi^{\prime}(\omega)\right\| \\
\leq\left\|T_{i}^{n}\left(\omega, \xi^{\prime}(\omega)\right)-\xi^{\prime \prime}(\omega)\right\|-\left\|\xi^{\prime}(\omega)-\xi^{\prime \prime}(\omega)\right\| \\
\quad-\left\|\xi^{\prime}(\omega)-\xi^{\prime \prime}(\omega)\right\|+\left\|\xi^{\prime}(\omega)-\xi^{\prime \prime}(\omega)\right\| \\
\leq\left(\left\|T_{i}^{n}\left(\omega, \xi^{\prime}(\omega)\right)-\xi^{\prime \prime}(\omega)\right\|-\left\|\xi^{\prime}(\omega)-\xi^{\prime \prime}(\omega)\right\|\right) \\
\quad+2\left(\left\|\xi^{\prime}(\omega)-\xi_{n_{2}^{\prime}}(\omega)\right\|+\left\|\xi_{n_{2}^{\prime}}(\omega)-\xi^{\prime \prime}(\omega)\right\|\right) \\
<\frac{\varepsilon}{5}+2\left(\frac{\varepsilon}{5}+\frac{\varepsilon}{5}\right)=\varepsilon .
\end{aligned}
$$

This implies that $T_{i}^{n}\left(\omega, \xi^{\prime}(\omega)\right) \rightarrow \xi^{\prime}(\omega)$ (as $\left.n \rightarrow \infty\right)$. Again since

$$
\begin{aligned}
\left\|T_{i}^{n}\left(\omega, \xi^{\prime}(\omega)\right)-T_{i}\left(\omega, \xi^{\prime}(\omega)\right)\right\| \\
\leq\left(\left\|T_{i}^{n}\left(\omega, \xi^{\prime}(\omega)\right)-\xi^{\prime \prime}(\omega)\right\|-\left\|\xi^{\prime}(\omega)-\xi^{\prime \prime}(\omega)\right\|\right) \\
\quad+\left\|\xi^{\prime}(\omega)-\xi^{\prime \prime}(\omega)\right\|+\left\|T_{i}\left(\omega, \xi^{\prime}(\omega)\right)-\xi^{\prime \prime}(\omega)\right\|
\end{aligned}
$$

for any $n \geq n_{2}^{\prime}$, by condition (34) and (42)-(44), we have

$$
\begin{aligned}
& \left\|T_{i}^{n}\left(\omega, \xi^{\prime}(\omega)\right)-T_{i}\left(\omega, \xi^{\prime}(\omega)\right)\right\| \\
& \leq \frac{\varepsilon}{5}+\left\|\xi^{\prime}(\omega)-\xi^{\prime \prime}(\omega)\right\|+L_{i}\left\|\xi^{\prime}(\omega)-\xi^{\prime \prime}(\omega)\right\|^{a_{i}} \\
& \leq \frac{\varepsilon}{5}+\left\|\xi^{\prime}(\omega)-\xi_{n_{2}^{\prime}}(\omega)\right\|+\left\|\xi_{n_{2}^{\prime}}(\omega)-\xi^{\prime \prime}(\omega)\right\| \\
& \quad+L_{i}\left(\left\|\xi^{\prime}(\omega)-\xi_{n_{2}^{\prime}}(\omega)\right\|+\left\|\xi_{n_{2}^{\prime}}(\omega)-\xi^{\prime \prime}(\omega)\right\|\right)^{a_{i}} \\
& <\varepsilon+L_{i} \cdot \varepsilon^{a_{i}} \quad \forall i \in I .
\end{aligned}
$$
$\infty)$.

This shows that $T_{i}^{n}\left(\omega, \xi^{\prime}(\omega)\right) \rightarrow T_{i}\left(\omega, \xi^{\prime}(\omega)\right)($ as $n \rightarrow$

From the uniqueness of limit, we have $\xi^{\prime}(\omega)=$ $T_{i}\left(\omega, \xi^{\prime}(\omega)\right)$; that is, $\xi^{\prime}(\omega)$ is a common fixed point of $T_{i}$ for all $i \in I$.

This completes the proof of the theorem. result.

If $\beta_{n}=0, v_{n}=0$, in Theorem 10, we obtain the following

Corollary 11. Let $X$ be a uniformly convex separable Banach space and let $C$ be a nonempty closed and convex subset of $X$. Let, for each $i \in I, T_{i}: D(T) \subset \Omega \times C \rightarrow C$ be asymptotically quasi-nonexpansive-type random operators satisfying the following condition: there exists constant $L_{i}>0$ and $a_{i}>0$ such that

$$
\left\|T_{i}(\omega, x)-\xi(\omega)\right\| \leq L_{i}\|x-\xi(\omega)\|^{a_{i}}
$$

for all $x \in D(T), \xi(\omega) \in \mathscr{F}$, and $i \in I$. Suppose that $\mathscr{F}=\bigcap_{i=1}^{N} \operatorname{RF}\left(T_{i}\right) \neq \phi$. Let $\xi_{0}: \Omega \rightarrow C$ be measurable and $\left\{\xi_{n}(\omega)\right\}$ defined by the implicit random iterative scheme with mixed errors

$$
\xi_{n}(\omega)=\alpha_{n} \xi_{n-1}(\omega)+\left(1-\alpha_{n}\right) T_{i}^{n}\left(\xi_{n}(\omega), \omega\right)+f_{n}, \quad n \geq 1,
$$

where $n=(k-1) N+i(i \in I)$ satisfying the following conditions:

(i) $s<\alpha_{n}<1-s$, for some $s \in(0,1 / 2)$;

(ii) $\sum_{n=0}^{\infty} \alpha_{n}<\infty$;

(iii) $\left\{f_{n}\right\}$ is bounded, $f_{n}=f_{n}^{\prime \prime}+f_{n}^{\prime \prime \prime}(n \geq 0)$ such that $\sum_{n=0}^{\infty}\left\|f_{n}^{\prime \prime}\right\|<\infty\left\|f_{n}^{\prime \prime \prime}\right\|=o\left(\alpha_{n}\right)$.

Then $\left\{\xi_{n}(\omega)\right\}$ converges strongly to a common random fixed point of $\mathscr{F}$ if and only if $\lim _{n \rightarrow \infty} \inf D\left(\xi_{n}(\omega), \mathscr{F}\right)=0$. 
Theorem 12. Let $X$ be a uniformly convex separable Banach space and let $C$ be a nonempty closed and convex subset of $X$ with $C+C \subset C$. Let $T_{i}: \mathrm{D}(T) \subset \Omega \times C \rightarrow C(i \in$ $I=\{1,2, \ldots, N\})$ be asymptotically quasi-nonexpansive-type random operator with $\mathscr{F}=\bigcap_{i=1}^{N} \operatorname{RF}\left(T_{i}\right) \neq \phi$ and there exists one member $T_{j}$ in $\left\{T_{i} \mid i \in I\right\}$ to be semicompact. Let $\xi_{0}: \Omega \rightarrow$ $C$ be measurable mapping and let $\left\{\xi_{n}\right\}$ be the sequence defined by the implicit random iterative scheme (14) with mixed errors satisfying the following conditions:

(i) $s<\alpha_{n}<1-s$, for some $s \in(0,1 / 2)$;

(ii) $\sum_{n=0}^{\infty} \alpha_{n}<\infty, \lim \sup _{n \rightarrow \infty} L \beta_{n}<1$;

(iii) $\left\{f_{n}\right\},\left\{f_{n}^{\prime}\right\}$ are bounded, $f_{n}=f_{n}^{\prime \prime}+f_{n}^{\prime \prime \prime}(n \geq 0)$ such that $\sum_{n=0}^{\infty}\left\|f_{n}^{\prime \prime}\right\|<\infty,\left\|f_{n}^{\prime \prime \prime}\right\|=o\left(\alpha_{n}\right)$ and $\sum_{n=0}^{\infty}\left\|f_{n}^{\prime}\right\|<\infty$.

Then the sequence $\left\{\xi_{n}\right\}$ converges strongly to a common random fixed point of the random operators $\left\{T_{i} \mid i \in I\right\}$.

Proof. From Lemma 9(1),

$$
\left\|\xi_{n}(\omega)-\xi(\omega)\right\| \leq\left\|\xi_{n-1}(\omega)-\xi(\omega)\right\|+\frac{M(\omega)}{s} \alpha_{n}+\frac{1}{2}\left\|f_{n}^{\prime \prime}\right\|
$$

for all $n \geq 0, \xi(\omega) \in \mathscr{F}$.

From Lemma 6 and conditions (ii), (iii), we have that $\lim _{n \rightarrow \infty}\left\|\xi_{n}(\omega)-\xi(\omega)\right\|$ exists. From Lemmas 7 and 8 for all $n>$ $n_{0}$ (where $n_{0}$ is the positive integer appeared in Lemma 9), we have

$$
\begin{aligned}
\| \xi_{n}(\omega) & -\xi(\omega) \|^{2} \\
= & \| \alpha_{n}\left(T_{i}^{k}\left(\omega, \eta_{n}(\omega)\right)+f_{n}-\xi(\omega)\right) \\
& +\left(1-\alpha_{n}\right)\left(\xi_{n-1}(\omega)+f_{n}-\xi(\omega)\right) \|^{2} \\
\leq & \alpha_{n}\left\|T_{i}^{k}\left(\omega, \eta_{n}(\omega)\right)+f_{n}-\xi(\omega)\right\|^{2} \\
& +\left(1-\alpha_{n}\right)\left\|\xi_{n-1}(\omega)+f_{n}-\xi(\omega)\right\|^{2} \\
& -\alpha_{n}\left(1-\alpha_{n}\right) g\left(\left\|T_{i}^{k}\left(\omega, \eta_{n}(\omega)\right)-\xi_{n-1}(\omega)\right\|\right) \\
\leq & \alpha_{n}\left(\left\|T_{i}^{k}\left(\omega, \eta_{n}(\omega)\right)-\xi(\omega)\right\|+\left\|f_{n}\right\|\right)^{2} \\
& +\left(1-\alpha_{n}\right)\left(\left\|\xi_{n-1}(\omega)-\xi(\omega)\right\|+\left\|f_{n}\right\|\right)^{2} \\
& -\alpha_{n}\left(1-\alpha_{n}\right) g\left(\left\|T_{i}^{k}\left(\omega, \eta_{n}(\omega)\right)-\xi_{n-1}(\omega)\right\|\right) \\
= & \alpha_{n}\left\{\left\|T_{i}^{k}\left(\omega, \eta_{n}(\omega)\right)-\xi(\omega)\right\|^{2}+2 c_{1}\left\|f_{n}\right\|\right\} \\
& +\left(1-\alpha_{n}\right)\left\{\left\|\xi_{n-1}(\omega)-\xi(\omega)\right\|^{2}+2 c_{2}\left\|f_{n}\right\|\right\} \\
& -\alpha_{n}\left(1-\alpha_{n}\right) g\left(\left\|T_{i}^{k}\left(\omega, \eta_{n}(\omega)\right)-\xi_{n-1}(\omega)\right\|\right)
\end{aligned}
$$

$$
\begin{aligned}
= & \alpha_{n}\left(\left\|T_{i}^{k}\left(\omega, \eta_{n}(\omega)\right)-\xi(\omega)\right\|^{2}-\left\|\eta_{n}(\omega)-\xi(\omega)\right\|^{2}\right) \\
& +\alpha_{n}\left\|\eta_{n}(\omega)-\xi(\omega)\right\|^{2}+\left(1-\alpha_{n}\right)\left\|\xi_{n-1}(\omega)-\xi(\omega)\right\|^{2} \\
& +2\left(c_{1} \alpha_{n}+c_{2}\left(1-\alpha_{n}\right)\right)\left\|f_{n}\right\| \\
& -\alpha_{n}\left(1-\alpha_{n}\right) g\left(\left\|T_{i}^{k}\left(\omega, \eta_{n}(\omega)\right)-\xi_{n-1}(\omega)\right\|\right)
\end{aligned}
$$

where

$$
\begin{gathered}
c_{1} \in\left(\left\|T_{i}^{k}\left(\omega, \eta_{n}(\omega)\right)-\xi(\omega)\right\|,\left\|T_{i}^{k}\left(\omega, \eta_{n}(\omega)\right)-\xi(\omega)\right\|+\left\|f_{n}\right\|\right), \\
c_{2} \in\left(\left\|\xi_{n-1}(\omega)-\xi(\omega)\right\|,\left\|\xi_{n-1}(\omega)-\xi(\omega)\right\|+\left\|f_{n}\right\|\right) .
\end{gathered}
$$

Substituting (24) into (51), using Lemma 8, we obtain

$$
\begin{aligned}
\| \xi_{n}(\omega) & -\xi(\omega) \|^{2} \\
\leq & \alpha_{n}\left(\left\|T_{i}^{k}\left(\omega, \eta_{n}(\omega)\right)-\xi(\omega)\right\|^{2}-\left\|\eta_{n}(\omega)-\xi(\omega)\right\|^{2}\right) \\
& +\alpha_{n}\left(\left\|\xi_{n}(\omega)-\xi(\omega)\right\|+\frac{\varepsilon}{5} \beta_{n}+\left\|f_{n}^{\prime}\right\|\right)^{2} \\
& +\left(1-\alpha_{n}\right)\left\|\xi_{n-1}(\omega)-\xi(\omega)\right\|^{2} \\
& +2\left(c_{1} \alpha_{n}+c_{2}\left(1-\alpha_{n}\right)\right)\left\|f_{n}\right\| \\
& -\alpha_{n}\left(1-\alpha_{n}\right) g\left(\left\|T_{i}^{k}\left(\omega, \eta_{n}(\omega)\right)-\xi_{n-1}(\omega)\right\|\right) \\
= & \alpha_{n}\left(\left\|T_{i}^{k}\left(\omega, \eta_{n}(\omega)\right)-\xi(\omega)\right\|^{2}-\left\|\eta_{n}(\omega)-\xi(\omega)\right\|^{2}\right) \\
& +\alpha_{n}\left(\left\|\xi_{n}(\omega)-\xi(\omega)\right\|+2 c_{3}\left(\frac{\varepsilon}{5} \beta_{n}+\left\|f_{n}^{\prime}\right\|\right)\right) \\
& +\left(1-\alpha_{n}\right)\left\|\xi_{n-1}(\omega)-\xi(\omega)\right\|^{2} \\
& +2\left(c_{1} \alpha_{n}+c_{2}\left(1-\alpha_{n}\right)\right)\left\|f_{n}\right\| \\
& -\alpha_{n}\left(1-\alpha_{n}\right) g\left(\left\|T_{i}^{k}\left(\omega, \eta_{n}(\omega)\right)-\xi_{n-1}(\omega)\right\|\right),
\end{aligned}
$$

where $c_{3} \in\left(\left\|\xi_{n}(\omega)-\xi(\omega)\right\|,\left\|\xi_{n}(\omega)-\xi(\omega)\right\|+(\varepsilon / 5) \beta_{n}+\left\|f_{n}^{\prime}\right\|\right)$. Substituting (23) and (26) into (53), we have

$$
\begin{aligned}
\left(1-\alpha_{n}\right) & \left\|\xi_{n}(\omega)-\xi(\omega)\right\|^{2} \\
\leq & \alpha_{n} \frac{\varepsilon}{5}\left(\left\|T_{i}^{k}\left(\omega, \eta_{n}(\omega)\right)-\xi(\omega)\right\|+\left\|\eta_{n}(\omega)-\xi(\omega)\right\|\right) \\
& +2 \alpha_{n}\left(c_{3}\left(\frac{\varepsilon}{5} \beta_{n}+\left\|f_{n}^{\prime}\right\|\right)+\left(c_{1} \alpha_{n}+c_{2}\left(1-\alpha_{n}\right)\right) \varepsilon_{n}\right) \\
& +\left(1-\alpha_{n}\right)\left\|\xi_{n-1}(\omega)-\xi(\omega)\right\|^{2} \\
& +2\left(c_{1} \alpha_{n}+c_{2}\left(1-\alpha_{n}\right)\right)\left\|f_{n}^{\prime \prime}\right\| \\
& -\alpha_{n}\left(1-\alpha_{n}\right) g\left(\left\|T_{i}^{k}\left(\omega, \eta_{n}(\omega)\right)-\xi_{n-1}(\omega)\right\|\right) .
\end{aligned}
$$


And so, we obtain

$$
\begin{aligned}
& \left\|\xi_{n}(\omega)-\xi(\omega)\right\|^{2} \\
& \leq \frac{\alpha_{n}}{1-\alpha_{n}} \frac{\varepsilon}{5}\left(\left\|T_{i}^{k}\left(\omega, \eta_{n}(\omega)\right)-\xi(\omega)\right\|+\left\|\eta_{n}(\omega)-\xi(\omega)\right\|\right) \\
& \quad+\frac{2 \alpha_{n}}{1-\alpha_{n}}\left(c_{3}\left(\frac{\varepsilon}{5} \beta_{n}+\left\|f_{n}^{\prime}\right\|\right)+\left(c_{1} \alpha_{n}+c_{2}\left(1-\alpha_{n}\right)\right) \varepsilon_{n}\right) \\
& \quad+\left\|\xi_{n-1}(\omega)-\xi(\omega)\right\|^{2}+\frac{2}{1-\alpha_{n}}\left(c_{1} \alpha_{n}+c_{2}\left(1-\alpha_{n}\right)\right)\left\|f_{n}^{\prime \prime}\right\| \\
& \quad-\alpha_{n} g\left(\left\|T_{i}^{k}\left(\omega, \eta_{n}(\omega)\right)-\xi_{n-1}(\omega)\right\|\right) .
\end{aligned}
$$

Therefore, from condition (i), we have

$$
\begin{aligned}
s g\left(\left\|T_{i}^{k}\left(\omega, \eta_{n}(\omega)\right)-\xi_{n-1}(\omega)\right\|\right) \\
<\alpha_{n} g\left(\left\|T_{i}^{k}\left(\omega, \eta_{n}(\omega)\right)-\xi_{n-1}(\omega)\right\|\right) \\
\leq\left\|\xi_{n-1}(\omega)-\xi_{n}(\omega)\right\|^{2}-\left\|\xi_{n}(\omega)-\xi(\omega)\right\|^{2} \\
\quad+\alpha_{n} \frac{\varepsilon}{5 s}\left(\left\|T_{i}^{k}\left(\omega, \eta_{n}(\omega)\right)-\xi(\omega)\right\|-\left\|\eta_{n}(\omega)-\xi(\omega)\right\|\right) \\
\quad+\alpha_{n} \frac{2}{s}\left(c_{3}\left(\frac{\varepsilon}{5} \beta_{n}+\left\|f_{n}^{\prime}\right\|\right)+\left(c_{1} \alpha_{n}+c_{2}\left(1-\alpha_{n}\right)\right) \varepsilon_{n}\right) \\
\quad+\frac{2}{s}\left(c_{1} \alpha_{n}+c_{2}\left(1-\alpha_{n}\right)\right)\left\|f_{n}^{\prime \prime}\right\| .
\end{aligned}
$$

Consequently,

$$
\lim _{n \rightarrow \infty} g\left(\left\|T_{i}^{k}\left(\omega, \eta_{n}(\omega)\right)-\xi_{n-1}(\omega)\right\|\right)=0 .
$$

Since $g$ is strictly increasing and continuous at 0 with $g(0)=$ 0 , it follows that

$$
\lim _{n \rightarrow \infty}\left\|T_{i}^{k}\left(\omega, \eta_{n}(\omega)\right)-\xi_{n-1}(\omega)\right\|=0
$$

Hence, from (14), we have

$$
\begin{aligned}
\left\|\xi_{n}(\omega)-\xi_{n-1}(\omega)\right\| \\
=\alpha_{n}\left\|\xi_{n-1}(\omega)-T_{i}^{k}\left(\omega, \eta_{n}(\omega)\right)\right\|+\left\|f_{n}\right\| \\
\leq \alpha_{n}\left(\left\|\xi_{n-1}(\omega)-T_{i}^{k}\left(\omega, \eta_{n}(\omega)\right)\right\|+\varepsilon_{n}\right) \\
\quad+\left\|f_{n}^{\prime \prime}\right\| \longrightarrow 0 \quad(\text { as } n \longrightarrow \infty)
\end{aligned}
$$

as well as $\left\|\xi_{n}(\omega)-\xi_{n+l}(\omega)\right\| \rightarrow 0$ (as $\left.n \rightarrow \infty\right)$ for all $l<2 N$.

For convenience, let $\sigma_{n}=\left\|T_{i}^{k}\left(\omega, \xi_{n}(\omega)\right)-\xi_{n-1}(\omega)\right\|$.

Since $T_{n}=T_{i}$ for $n=(k-1) N+i$, we have $\sigma_{n}=$ $\left\|T_{n}^{k}\left(\omega, \xi_{n}(\omega)\right)-\xi_{n-1}(\omega)\right\|$.
Notice that

$$
\begin{aligned}
&\left\|T_{n}^{k}\left(\omega, \xi_{n}(\omega)\right)-\xi_{n-1}(\omega)\right\| \\
& \leq\left\|T_{n}^{k}\left(\omega, \xi_{n}(\omega)\right)-T_{n}^{k}\left(\omega, \eta_{n}(\omega)\right)\right\| \\
&+\left\|T_{n}^{k}\left(\omega, \eta_{n}(\omega)\right)-\xi_{n-1}(\omega)\right\| \\
& \leq L\left\|\xi_{n}(\omega)-\eta_{n}(\omega)\right\| \\
&+\left\|T_{n}^{k}\left(\omega, \eta_{n}(\omega)\right)-\xi_{n-1}(\omega)\right\| \\
& \leq L\left\|\beta_{n} \xi_{n}(\omega)-\beta_{n} T_{n}^{k}\left(\omega, \xi_{n}(\omega)\right)-f_{n}^{\prime}\right\| \\
&+\left\|T_{n}^{k}\left(\omega, \eta_{n}(\omega)\right)-\xi_{n-1}(\omega)\right\| \\
& \leq L \beta_{n}\left(\left\|\xi_{n}(\omega)-\xi_{n-1}(\omega)\right\|\right. \\
&\left.\quad+\left\|\xi_{n-1}(\omega)-T_{n}^{k}\left(\omega, \xi_{n}(\omega)\right)\right\|\right) \\
&+L\left\|f_{n}^{\prime}\right\|+\left\|T_{n}^{k}\left(\omega, \eta_{n}(\omega)\right)-\xi_{n-1}(\omega)\right\| \quad \forall n>n_{0} .
\end{aligned}
$$

Thus, by $\lim \sup _{n \rightarrow \infty} L \beta_{n}<1$, we have

$$
\lim _{n \rightarrow \infty} \sigma_{n}=\lim _{n \rightarrow \infty}\left\|T_{n}^{k}\left(\omega, \xi_{n}(\omega)\right)-\xi_{n-1}(\omega)\right\|=0 .
$$

Therefore, for $n>N$, we have

$$
\begin{aligned}
& \left\|\xi_{n-1}(\omega)-T_{n}\left(\omega, \xi_{n}(\omega)\right)\right\| \\
& \leq\left\|\xi_{n-1}(\omega)-T_{n}^{k}\left(\omega, \xi_{n}(\omega)\right)\right\| \\
& \quad+\left\|T_{n}^{k}\left(\omega, \xi_{n}(\omega)\right)-T_{n}\left(\omega, \xi_{n}(\omega)\right)\right\| \\
& \leq \sigma_{n}+L\left\|T_{n}^{k-1}\left(\omega, \xi_{n}(\omega)\right)-\xi_{n}(\omega)\right\| \\
& \leq \sigma_{n}+L\left\{\left\|T_{n}^{k-1}\left(\omega, \xi_{n}(\omega)\right)-T_{n-N}^{k-1}\left(\omega, \xi_{n-N}(\omega)\right)\right\|\right. \\
& \quad+\left\|T_{n-N}^{k-1}\left(\omega, \xi_{n-N}(\omega)\right)-\xi_{(n-N)-1}(\omega)\right\| \\
& \left.\quad+\left\|\xi_{(n-N)-1}(\omega)-\xi_{n}(\omega)\right\|\right\} .
\end{aligned}
$$

Notice that $n \equiv(n-N)(\bmod N)$. Thus, $T_{n}=T_{n-N}$ and the previous inequality becomes

$$
\begin{aligned}
& \left\|\xi_{n-1}(\omega)-T_{n}\left(\omega, \xi_{n}(\omega)\right)\right\| \\
& \leq \sigma_{2}+L^{2}\left\|\xi_{n}(\omega)-\xi_{n-N}(\omega)\right\| \\
& \quad+L \sigma_{n-N}+L\left\|\xi_{n}(\omega)-\xi_{(n-N)-1}(\omega)\right\|
\end{aligned}
$$

which yields that

$$
\lim _{n \rightarrow \infty}\left\|\xi_{n-1}(\omega)-T_{n}\left(\omega, \xi_{n}(\omega)\right)\right\|=0 .
$$

From

$$
\begin{aligned}
\left\|\xi_{n}(\omega)-T_{n}\left(\omega, \xi_{n}(\omega)\right)\right\| \leq & \left\|\xi_{n}(\omega)-\xi_{n-1}(\omega)\right\| \\
& +\left\|\xi_{n-1}(\omega)-T_{n}\left(\omega, \xi_{n}(\omega)\right)\right\|,
\end{aligned}
$$


it follows that

$$
\lim _{n \rightarrow \infty}\left\|\xi_{n}(\omega)-T_{n}\left(\omega, \xi_{n}(\omega)\right)\right\|=0 .
$$

Furthermore, for all $l \in I$, we obtain

$$
\begin{aligned}
&\left\|\xi_{n}(\omega)-T_{n+l}\left(\omega, \xi_{n}(\omega)\right)\right\| \\
& \leq\left\|\xi_{n}(\omega)-\xi_{n+l}(\omega)\right\|+\left\|\xi_{n+l}(\omega)-T_{n+l}\left(\omega, \xi_{n+l}(\omega)\right)\right\| \\
& \quad+\left\|T_{n+l}\left(\omega, \xi_{n+l}(\omega)\right)-T_{n+l}\left(\omega, \xi_{n}(\omega)\right)\right\| \\
& \leq(1+L)\left\|\xi_{n}(\omega)-\xi_{n+l}(\omega)\right\| \\
& \quad+\left\|\xi_{n+l}(\omega)-T_{n+l}\left(\omega, \xi_{n+l}(\omega)\right)\right\|
\end{aligned}
$$

which implies that

$$
\lim _{n \rightarrow \infty}\left\|\xi_{n}(\omega)-T_{n+l}\left(\omega, \xi_{n}(\omega)\right)\right\|=0 \quad \forall l \in I .
$$

Thus,

$$
\lim _{n \rightarrow \infty}\left\|\xi_{n}(\omega)-T_{n}\left(\omega, \xi_{l}(\omega)\right)\right\|=0 \quad \forall l \in I .
$$

By the hypothesis that there exists $T_{j}$ in $\left\{T_{i}: i \in I\right\}$ to be semicompact, we may assume that $T_{l}$ is semicompact without loss of generality. By the definition of semicompactness, there exists a subsequence $\left\{\xi_{n_{j}}\right\}$ of $\left\{\xi_{n}\right\}$ such that $\xi_{n_{j}} \rightarrow \xi^{*} \in C$. By (69) again, we have

$$
\begin{aligned}
& \left\|\xi^{*}(\omega)-T_{l}\left(\omega, \xi^{*}(\omega)\right)\right\| \\
& \quad=\lim _{j \rightarrow \infty}\left\|\xi_{n_{j}}(\omega)-T_{l}\left(\omega, \xi_{n_{j}}(\omega)\right)\right\|=0 \quad(\forall 1 \leq l \leq N) .
\end{aligned}
$$

It shows that $\xi^{*}(\omega) \in \mathscr{F}$. Replace $\xi(\omega)$ by $\xi^{*}(\omega)$ in $(50)$; from Lemma 6, we easily know that $\lim _{n \rightarrow \infty}\left\|\xi_{n}(\omega)-\xi^{*}(\omega)\right\|$ exists so that $\left\{\xi_{n}\right\}$ converges strongly to a common random fixed point $\xi^{*}(\omega) \in \mathscr{F}$.

This completes the proof of the theorem.

Remark 13. Our results extend and improve the corresponding results of Plubtieng et al. [12] and Beg and Thakur [13] to the case of a more general class of asymptotically quasinonexpansive random operators considered in this paper. Our results also generalize the results of Saluja and Nashine [14] to the class of more general class of asymptotically quasinonexpansive-type random operators and two-step implicit random iteration process considered in this paper.

\section{Acknowledgment}

The authors are thankful to the anonymous referees for their critical remarks and valuable comments, which helped them to improve the presentation of this paper.

\section{References}

[1] A. Špaček, "Zufällige gleichungen," Czechoslovak Mathematical Journal, vol. 5, no. 80, pp. 462-466, 1955.
[2] A. T. Bharucha-Reid, "Fixed point theorems in probabilistic analysis," Bulletin of the American Mathematical Society, vol. 82, no. 5, pp. 641-657, 1976.

[3] O. Hanš, "Random fixed point theorems," in Proceedings of the 1st Prague Conference on Information Theory, Statistical Decision Functions, Random Processes, pp. 105-125, Czechoslovak Academy of Science, Prague, Czech Republic, 1957.

[4] O. Hanš, "Random operator equations," in Proceedings of the 4th Berkeley Symposium on Mathematical Statistics and Probability, vol. 2, pp. 185-202, University California Press, Berkeley, Calif, USA, 1961.

[5] B. S. Choudhury, "Convergence of a random iteration scheme to a random fixed point," Journal of Applied Mathematics and Stochastic Analysis, vol. 8, no. 2, pp. 139-142, 1995.

[6] I. Beg, "Approximation of random fixed points in normed spaces," Nonlinear Analysis. Theory, Methods \& Applications, vol. 51, no. 8, pp. 1363-1372, 2002.

[7] B. S. Choudhury, "Random Mann iteration scheme," Applied Mathematics Letters, vol. 16, no. 1, pp. 93-96, 2003.

[8] H. Duan and G. Li, "Random Mann iteration scheme and random fixed point theorems," Applied Mathematics Letters, vol. 18, no. 1, pp. 109-115, 2005.

[9] G. Li and H. Duan, "On random fixed point theorems of random monotone operators," Applied Mathematics Letters, vol. 18, no. 9, pp. 1019-1026, 2005.

[10] S. Itoh, "A random fixed point theorem for a multivalued contraction mapping," Pacific Journal of Mathematics, vol. 68, no. 1, pp. 85-90, 1977.

[11] I. Beg and M. Abbas, "Iterative procedures for solutions of random operator equations in Banach spaces," Journal of Mathematical Analysis and Applications, vol. 315, no. 1, pp. 181-201, 2006.

[12] S. Plubtieng, P. Kumam, and R. Wangkeeree, "Approximation of a common random fixed point for a finite family of random operators," International Journal of Mathematics and Mathematical Sciences, vol. 2007, Article ID 69626, 12 pages, 2007.

[13] I. Beg and B. S. Thakur, "Solution of random operator equations using general composite implicit iteration process," International Journal of Modern Mathematics, vol. 4, no. 1, pp. 19-34, 2009.

[14] G. S. Saluja and H. Nashine, "Random fixed point theorems for a finite family of asymptotically quasi-nonexpansive in the intermediate sense random operators," Random Operators \& Stochastic Equations, vol. 20, no. 4, pp. 329-346, 2012.

[15] K. Goebel and W. A. Kirk, "A fixed point theorem for asymptotically nonexpansive mappings," Proceedings of the American Mathematical Society, vol. 35, pp. 171-174, 1972.

[16] J. Li, J. K. Kim, and N. J. Huang, "Iteration scheme for a pair of simultaneously asymptotically quasi-nonexpansive type mappings in Banach spaces," Taiwanese Journal of Mathematics, vol. 10, no. 6, pp. 1419-1429, 2006.

[17] H. K. Xu, "Inequalities in Banach spaces with applications," Nonlinear Analysis. Theory, Methods \& Applications, vol. 16, no. 12, pp. 1127-1138, 1991.

[18] Z. Huang, "Mann and Ishikawa iterations with errors for asymptotically nonexpansive mappings," Computers \& Mathematics with Applications, vol. 37, no. 3, pp. 1-7, 1999. 


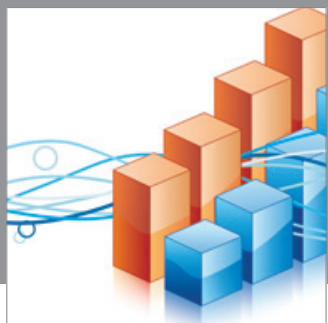

Advances in

Operations Research

mansans

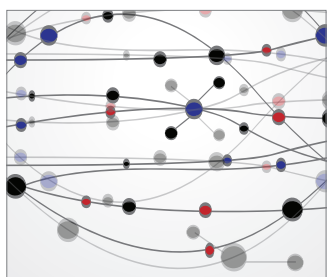

The Scientific World Journal
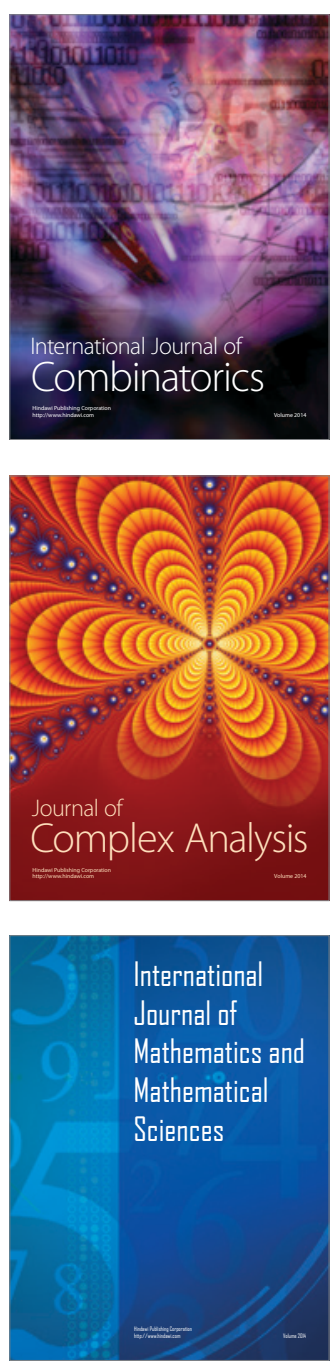
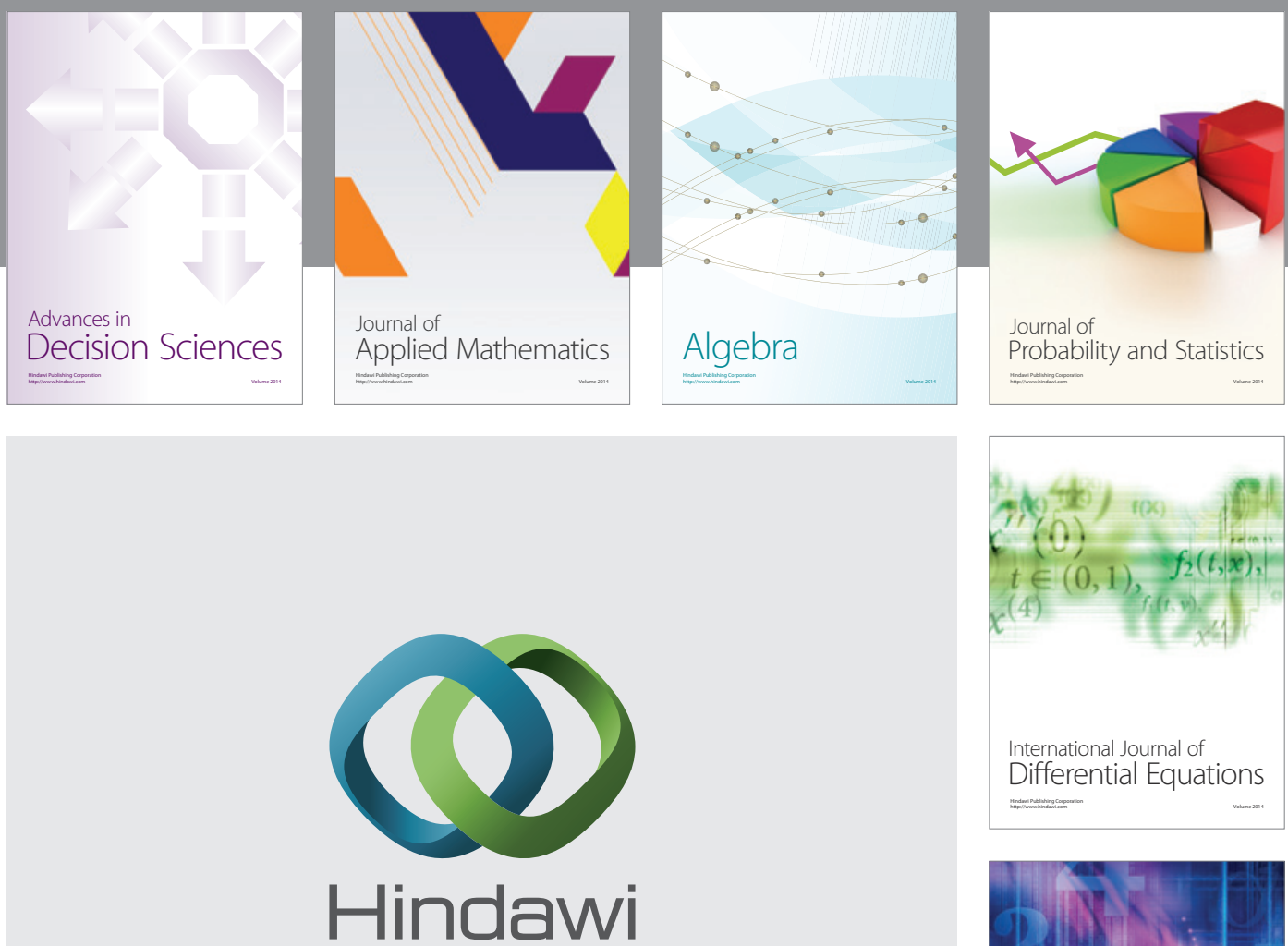

Submit your manuscripts at http://www.hindawi.com
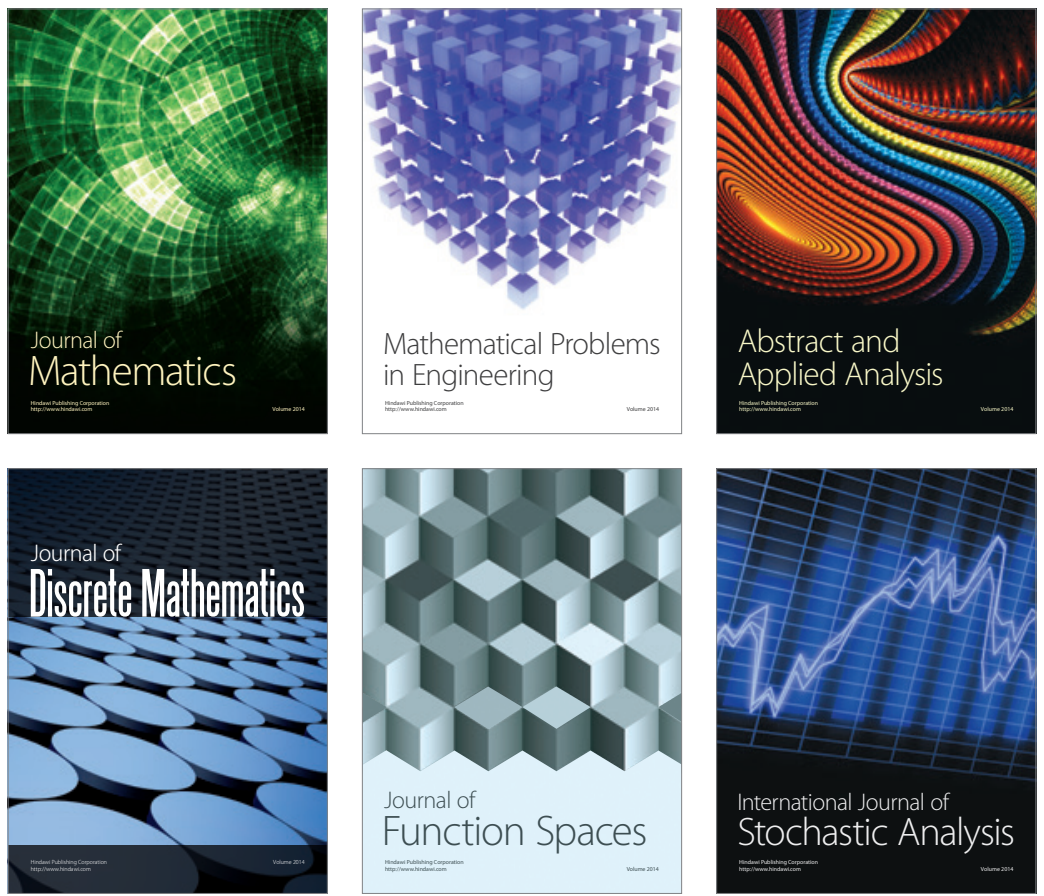

Journal of

Function Spaces

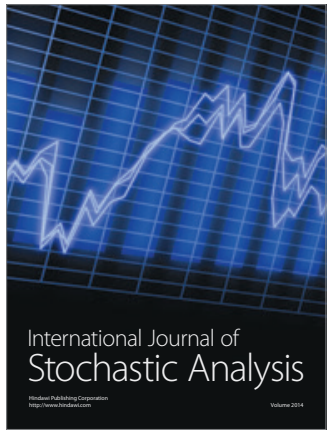


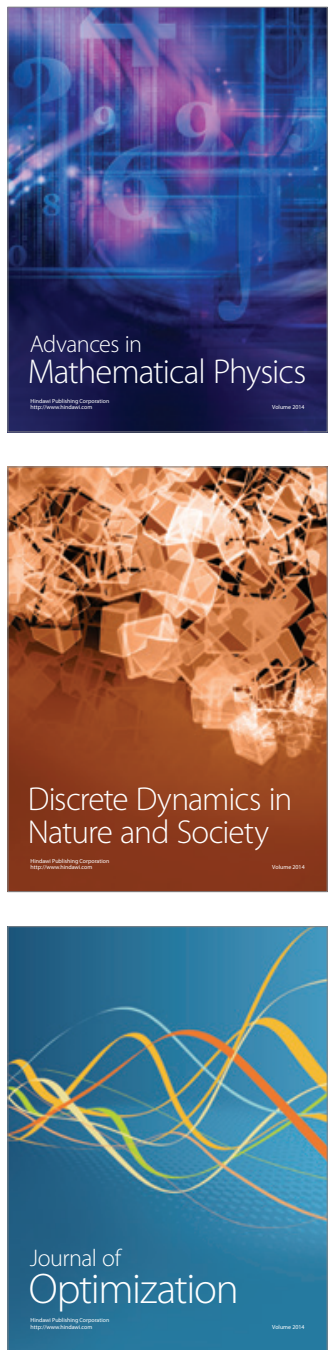